\section{Commentary: Failing to forecast}

\author{
Jinny S. Ha, MD, and Christopher R. Johnson, MD
}

Matthews and Hess ${ }^{1}$ bring up 2 topics that we as surgeons struggle with all too often yet seldom discuss: our own health and how to effectively discuss difficult prognoses with our patients. In particular, they demonstrate through personal experience how these concepts can be so strongly interconnected. Their story brings to mind the book When Breath Becomes Air by $\mathrm{Dr}$ Kalanithi, ${ }^{2}$ also a surgical resident in the midst of training when diagnosed with metastatic non-small cell lung cancer. Both provide insight into the challenges of dealing with a new diagnosis, navigating its impact on our personal and professional lives, and placing ourselves in the position of the patient. This role is particularly complex for physicians because we occupy a unique space, being both the patient surprised and flooded with the emotion of such news and the clinician attempting to examine, understand, and address the biology of disease. Ultimately, the experience shows us that we want the same thing as our patients: the clarity and peace of mind to move forward, to make decisions regarding treatment and plans for life, and to maintain hope.

Second, the task of disclosing a difficult prognosis is discussed. In doing so, the question is posed "When does preserving patient autonomy through informed consent violate primum non nocere?" Put more broadly, what is our ability to have these conversations and how does that affect our patients? Perceptions of prognostic information can affect a broad range of parameters, including survival time, recurrence rates, and quality of life. This begs the question not if or what information we should share, but rather how we can more effectively communicate with patients, families, and colleagues in these situations. Understanding the prognosis of one's disease is important for a number of reasons: (1) helps develop a care plan; (2) provides common language for multidisciplinary care; and (3) guides the allocation of resources, policies, and programs in healthcare delivery. ${ }^{3}$

\footnotetext{
From the Division of Thoracic Surgery, The Johns Hopkins School of Medicine, Baltimore, Md.

Disclosures: Authors have nothing to disclose with regard to commercial support.

Received for publication Feb 5, 2020; accepted for publication Feb 6, 2020; available ahead of print Feb 14, 2020.

Address for reprints: Jinny S. Ha, MD, Division of Thoracic Surgery, The Johns Hop-

kins School of Medicine, $600 \mathrm{~N}$ Wolfe St, Blalock 240, Baltimore, MD 21287 (E-mail: jha1@jhmi.edu).

J Thorac Cardiovasc Surg 2020;160:877 0022-5223/ $\$ 36.00$

Copyright (c) 2020 Published by Elsevier Inc. on behalf of The American Association for Thoracic Surgery

https://doi.org/10.1016/j.jtcvs.2020.02.004
}

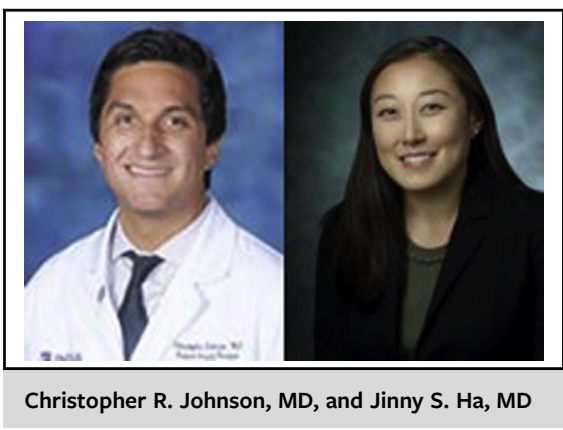

CENTRAL MESSAGE

Discussing prognosis with a patient is a difficult and delicate task. Strategies and guidelines are needed to better equip physicians to address prognosis in a meaningful and therapeutic manner.

Vasista and colleagues ${ }^{4}$ present what may provide a framework for such conversations. In a population of patients with cancer, they evaluated a provider's ability to accurately estimate survival. They found that observed survival predictably fell into 1 of 3 categories: a worst case, typical, or best case scenario, each representing a relative ratio of their estimated survival. Rather than the vague, although often true, statement of "it is difficult to say," we can say that there are at least a few scenarios that warrant further consideration. The foundation of these conversations needs to be honesty, clarity, empathy, patience, and the development of a shared trust. ${ }^{5}$

Matthews and Hess ${ }^{1}$ provide us with a powerful reminder to reflect on our approach to these conversations. In doing so, and with further scholarly work in the field, we can appropriately inform our patients while helping them maintain hope and peace in the face of new challenges and uncertainty.

\section{References}

1. Matthews CR, Hess PJ. Thirty-three, zero, nine. J Thorac Cardiovasc Surg. 2020; 160:871-5.

2. Kalanthi P. When Breath Becomes Air. Toronto: CNIB; 2016.

3. Thai V, Wolch G, Tatumi Y. Survival prediction of end stage cancer patients: a quick review. J Palliat Care Med. 2013;3:164.

4. Vasista A, Stockler M, Martin A, Pavlakis N, Sjoquist K, Goldstein D, et al. Accuracy and prognostic significance of oncologists' estimates and scenarios for survival time in advanced gastric cancer. Oncologist. 2019;24:e1102-7.

5. Glare P, Sinclair C, Downing M, Stone P, Maltoni M, Vigano A Predicting survival in patients with advanced disease. Eur $J$ Cancer 2008;44:1146-56. 